\title{
Promoting and Supporting Computer Science Among Middle School Girls of Color
}

\author{
Initial Findings from BRIGHT-CS
}

\author{
Veronica Madrigal \\ Education First \\ Consulting \\ Washington DC USA \\ vmadrigal@education- \\ first.com
}

\author{
Ryoko Yamaguchi \\ Plus Alpha Research \& \\ Consulting \\ Arlington VA USA \\ ryamaguchi@plusalpha \\ research.com
}

\author{
Adam Hall \\ Plus Alpha Research \& \\ Consulting \\ Arlington VA USA \\ ahall@plusalpha \\ research.com
}

\author{
Jamika Burge \\ blackcomputeHER \\ Washington DC USA \\ jamika.burge@ \\ gmail.com
}

\begin{abstract}
BRIGHT-CS (Building Student Retention through Individuated

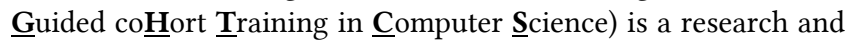
development project that 1) creates a computer science learning ecosystem for middle school Black girls and other girls of color and 2) researches the merits of the ecosystem in supporting persistence in CS to determine best practices for broadening participation to other marginalized student groups in computing. First, this paper describes the BRIGHT-CS program, from the structural, instructional, and curricular designs of the program to partnerships with local and community organizations that make up the ecosystem. Second, it presents the initial findings of research on the program and its impacts on student outcomes such as social-emotional attributes associated with persistence. The study employs a multi-method descriptive design. Data includes student surveys, interviews (from students, parents, instructors, teachers, and mentors), artifact reviews, and student observations. The study includes 46 students across four middle schools in two states. At the start of the program, $37 \%$ of the students reported being very interested in CS, and $72 \%$ reported being very confident in learning CS. This is much higher than a national benchmark of students. After four months of program implementation, the qualitative results show a more nuanced picture of the value of a learning ecosystem. First, the ecosystem offers implicit messaging about equity and success. Second, the ecosystem offers explicit messaging about personal challenges and improvement. Third, following the implicit and explicit messaging to students, students went from naïve confidence to authentic self-efficacy in CS.
\end{abstract}

Permission to make digital or hard copies of all or part of this work for personal or classroom use is granted without fee provided that copies are not made or distributed for profit or commercial advantage and that copies bear this notice and the full citation on the first page. Copyrights for components of this work owned by others than ACM must be honored. Abstracting with credit is permitted. To copy otherwise, or republish, to post on servers or to redistribute to lists, requires prior specific permission and/or a fee. Request permissions from Permissions@acm.org.

SIGCSE '20, March 11-14, 2020, Portland, OR, USA

(C) 2020 Association for Computing Machinery.

ACM ISBN 978-1-4503-6793-6/20/03...\$15.00

https://doi.org/10.1145/3328778.3366855

\section{CCS CONCEPTS}

- Applied computing • computer science education

\section{KEYWORDS}

Learning environment; K-12 instruction; gender and diversity; descriptive; qualitative

\section{ACM Reference format:}

Veronica Madrigal, Ryoko Yamaguchi, Adam Hall and Jamika Burge. 2020. Promoting and Supporting Computer Science Among Middle School Girls of Color: Initial Findings from BRIGHT-CS. In Proceedings of the 51st ACM Technical Symposium on Computer Science Education (SIGCSE'20), March 11-14, 2020, Portland, OR, USA. ACM, New York, NY, USA, 7 pages. https://doi.org/10.1145/3328778.3366855.

\section{Introduction}

Black college freshman interest in computer science (CS) has been declining for almost 20 years-to an all-time low of 9\% in 2014 [1]. There is clearly a need to start integrating CS into the K-12 public education system earlier, when Black students and parents are highly interested in learning about CS [2].

To understand the decline, this paper considers two areas within the K-12 context: 1) the importance of the middle school setting; and 2) the structural, instructional, and curricular barriers for students of color to access and excel at CS.

First, the middle school grades (often grades 6-8 or 7-8) are a critical transition point academically, developmentally, and socially for students [3]. While high school students can learn CS through career and technical education (CTE) courses, dual enrollment with community colleges, and AP CS courses [4], elementary students have limited exposure, often only through informal settings like summer camps, Saturday programs, or possibly afterschool clubs. Thus, middle school, as an important transition point, could serve to encourage and prepare more students to pursue an interest in CS. This, in turn, could support high school and then post-secondary CS interest and persistence. Yet middle school students often lack opportunities to explore CS and prepare for the rigors of high school CS coursework. 
Second, students of color, and Black students specifically, face structural, instructional and curricular barriers to accessing CS, as evidenced by fewer opportunities to learn computer science at school [4]; a "deeply flawed" computer science teaching certification process [5] and limited professional development for CS teachers, which can hinder access to highly qualified teachers; and math [6] and science curricula [7] that advance a racial hierarchy of math and science ability [6]. These barriers help explain the pervasive gaps in school performance [8], discipline [9], and educational services observed for Black students [10-12].

This paper presents the initial findings of a program designed for middle school girls of color, specifically for Black girls. ${ }^{1}$ The

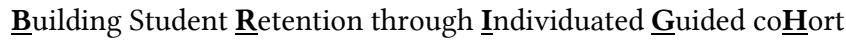

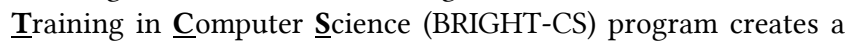
comprehensive computer science and empowerment program by building partnerships with schools, universities, non-profits, and community organizations in a local area. BRIGHT-CS recognizes that to engage Black girls in computing, it cannot rely on "oneoff" experiences such as a coding day, a Hackathon event, or a coding camp, the effects of which often fade over time [13, 14]. Instead, engagement must be an on-going process that is part of a larger learning ecosystem of students, parents, community, and school.

The guiding research question for this study is: What are the features of an effective CS learning ecosystem to promote and support interest in computer science among middle school girls of color? Of particular interest is understanding the factors that support CS interest and learning.

\subsection{BRIGHT-CS theoretical framework}

Research demonstrates that learning is not limited to the school structure or day; deep learning develops across multiple settings and timeframes. This type of deep learning and engagement is leveraged when resources are aligned in a STEM learning ecosystem $[15,16]$. Building on the NRC model of a STEM learning ecosystem, the BRIGHT-CS theoretical framework outlines a CS learning ecosystem specifically for middle school girls of color, as shown in Figure 1.

1.1.1 Developing an ecosystem focused on the intersectionality of race and gender in adolescence. Adolescence is a time of many dynamic changes [17]. Not only do students experience physical, social, and cognitive changes, but their schooling experience changes as coursework becomes more rigorous, teachers' expectations change, class schedules become more intense, and expected parent roles change from more to less involved [3]. Rather than nurturing interest in a specific subject or topic area, research has shown the importance of nurturing "possible selves" [24] and growth mindset [25] to persistence and academic success.

Within this context of adolescent development, the social emotional development and needs of Black girls and other girls of color are also important to address [18, 19]. For girls of color, in addition to their identity formation at large, their development includes making sense of their racial and gender experiences such

1 Reference to "Black girls" includes students of African origin or ancestry, including but not limited to African American, African immigrant, Hispanic non-White, and Caribbean.

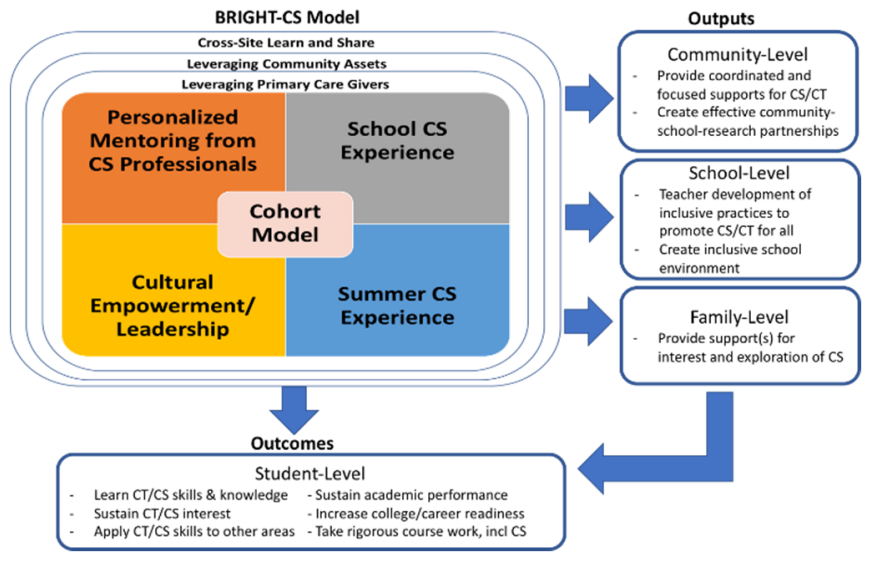

Figure 1: Conceptual framework of the BRIGHT-CS learning ecosystem

as stereotype threat [20], imposter syndrome [21], and explicit and implicit biases [23]-especially when there are few of them in advanced and gifted classes at school $[11,22]$.

BRIGHT-CS starts by forming a cohort of girls of color from the same middle school (grades 6-8). The girls come together for a weekly 9-month afterschool program at their school, a twoweek summer experience at a local university or non-profit organization, and on-going mentoring from women and persons of color who are local community leaders, computer scientists, and entrepreneurs. As an ecosystem, the program provides girls and their families with deep learning and engagement through partnerships between schools, local universities and community organizations. The program curriculum, which focuses on solving problems with technology, also empowers girls with valuable leadership skills.

The goal of the program is not only to build computer science interest, knowledge, and skills, but to also promote and support social emotional development. In so doing, this program seeks to reinforce positive pro-social behaviors including academic performance, college/career readiness, and taking rigorous coursework in high school including CS courses (see outcomes in Figure 1). However, it is not enough simply to create a CS program for Black girls and other girls of color, which can have very limited sustained impacts with distinct fade-out effects [13, 14]. It is also important to address instructional, structural and curricular barriers to accessing CS that girls of color often face.

1.1.2 Addressing instructional barriers to access and opportunity. Culturally responsive instructional practices support engagement and motivation, particularly for Black and Latina girls [26]. From validating student's hard work and growth [25] to providing affirmations [29] and feedback [30] that promote motivation and learning, culturally responsive practices teach students to be learners [31]. As Ladson-Billings [27] noted, many see culturally relevant pedagogy as "just good teaching." 
However, developing culturally responsive practices is challenging [27, 28].

The BRIGHT-CS program features collaborative hands-on learning activities, with students presenting their work to community and school leaders, mentors, and their parents. Therefore, unlike a traditional pedagogical approach wherein teachers are experts didactically serving content, instructors are encouraged to act as a coach and mentor-not only teaching computer science skills, but also helping students create an application and achieve leadership and social emotional development in the process.

1.1.3 Addressing structural and curricular barriers to access and opportunity. The BRIGHT-CS framework creates an ecosystem designed to address structural and curricular barriers that Black girls and other girls of color face. Structural barriers for Black girls and girls of color include policies and practices that result in a "chilly environment" for success [32], such as disproportionality in discipline [9], higher rates of participation in special education services $[10,12]$, and extremely low participation in gifted services [11, 22]. Curricular barriers can include activities, materials, and assessments that do not reflect the lived experiences of students.

The BRIGHT-CS framework creates a CS learning ecosystem by building partnerships with local universities, community organizations, and school systems; working with Black women in computing who serve as mentors and instructors; and creating a curriculum that features Black women technologists and entrepreneurs as case studies. In light of the typical homogenous K-12 teaching body [33], this ecosystem purposefully creates an environment wherein students are surrounded by mentors, instructors, and even curricular and classroom materials that reflect their experiences. This partnership is practical, since it provides programming for students that includes capstone projects designed in conjunction with school staff, summer camps created with community organizations and local universities, and mentoring by local leaders whom students can identify with. This partnership is also strategic, since it allows for ongoing community needs and asset assessment to gather information about other opportunities to distribute to the girls and their families.

The result of creating the CS learning ecosystem is the outputs (see outputs in Figure 1). The research team anticipates a multilevel set of immediate outputs from creating and sustaining a CS learning ecosystem. First, the community-level outputs will include the creation of an effective community-school-research partnership that will help to provide coordinated and focused programming in CS geared towards Black girls. Second, the school-level outputs will include teacher experience in inclusive instructional practices to promote $\mathrm{CS}$ for all students and an active stance to promote an inclusive school culture. Third, the familylevel will include primary care givers with community information and exposure to CS so they have the tools needed to support girls of color in their college and career aspirations.

${ }^{2}$ Data collection and analysis included all students, including the single boy in the program.

\section{Methods}

\subsection{Sample}

The sample is composed of 46 students from four urban middle schools (two each in New York and Virginia). These students applied to be part of the BRIGHT-CS program between November 2018 and the program launch in January 2019. Of the 46 students, all are girls except for one boy. ${ }^{2}$ The majority of the students are Black girls (65\%), with 20\% Hispanic, $11 \%$ White, and $4 \%$ Asian and multi-racial. Thirty-percent $(30 \%)$ self-reported that they speak another language at home. ${ }^{3}$

Benchmarking against a national sample of 771 girls surveyed by Google and Gallup on attitudes and experiences in computer science [34], there were marked differences in the BRIGHT-CS student sample. First, over 2 in 3 BRIGHT-CS students were told by teachers and parents that they would be good at computer science (63\% and 65\% respectively), compared to the benchmark sample of only about 1 in 4 girls. The BRIGHT-CS students were also very interested in learning CS (37\%) compared to the benchmark sample (16\%), and very confident in learning CS (72\%) compared to the benchmark sample (48\%). Differences are not surprising given that, unlike the benchmark sample, BRIGHT-CS students self-selected into a CS program.

\subsection{Data Collection and Analysis}

As a multi-method study, this study collected both quantitative and qualitative data from students who had parental consent. First, the research team obtained the quantitative data during the student application process. The application gathered student demographic data, perceptions of math and reading taken from the NCES Education Longitudinal Study survey, and experiences in computer science taken from the Google/Gallup survey [34]. This obtained quantitative data on all 46 students in the program. The purpose of the quantitative data was to measure baseline student characteristics to provide context to the qualitative data. Quantitative data (i.e., student surveys) were analyzed using descriptive statistics.

Qualitative data was obtained during the BRIGHT-CS program activities and included interviews with students $(\mathrm{N}=31)$, parents $(\mathrm{N}=2)$, community mentors $(\mathrm{N}=7)$, school staff sponsors $(\mathrm{N}=4)$, and program instructors $(\mathrm{N}=3)$ at multiple time points across four months. In addition to the interviews, researchers collected program documents, computing artifacts, and weekly observations of afterschool and summer sessions. Qualitative data (i.e., notes taken during observations, interviews, artifacts, and documents) were digitized. Then, the research team created a "start list" [35, 36] based on the main components of the project and moved into core ideas, themes, and cross-analysis [37]. The research team met to finalize the themes, with $100 \%$ agreement on the coding and interpretation. Validation and "trustworthiness" of coding and interpretation were verified in face-validity meetings with advisory board members and stakeholders [35, 38].

\footnotetext{
${ }^{3}$ Other languages included Spanish, Somalian, Amharic, Urdu, Bengali, Tigrinya (an East African language), Haitian Creole, Farsi, and Hausa.
} 


\section{Results}

The interim results of the CS learning ecosystem approach show the following themes: 1) Implicit messaging about equity and success, 2) Explicit messaging about personal challenges and improvement, and 3) Naïve confidence to authentic self-efficacy.

\subsection{Implicit messaging about equity and success}

Women and girls of color experience steady inundation of messages that their gender and race disqualify them from success in STEM+CS [32]. In interviews with BRIGHT-CS mentors who are women of color professionally employed in computer science, all described personal experiences of prejudice tied to their gender and/or race. In particular, several cited implicit messages they received that women of color do not bring value to the pursuit of knowledge or solutions in STEM+CS disciplines, only deficits to be fixed. "I get these guys all the time that try to put me on display as someone who doesn't know what they're doing," said one mentor. "I'm in a CS PhD program, and, when it's hard questions, people overlook me," said another mentor. "The question pops in my head, Do they not see me in this space as having valuable input to solve their problem? The stigma, thinking women of color just don't have anything to offer [transfers] to children - even if not verbally directed at them, they see messages and it becomes internalized." In school, these messages can take various forms. The staff sponsor for BRIGHT-CS at one school site observed that his Black female students may experience these messages via a lack of programs for nurturing their academic interests rather than, for example, their athletic interests (e.g., cheerleading). When academic programs do target students of color, he continued, they can come across as more concerned with correcting deficits than nurturing potential. "There is a negative connotation," he said. "What I don't want is for students [of color] to think that they are the problem." In another site, a mentor observed that several participants' interest had been dampened by a CS teacher who treated their questions like misbehavior, not signals of interest. "It was a, 'You don't know this? How dare you' type of thing. They didn't feel valued." Together, these messages prime girls of color for feelings of stereotype threat and may trigger behaviors that, in seeking to avoid confirming stereotypes, prevent them from deeply exploring their interest in STEM+CS. For example, interviews in two sites demonstrated that a significant number of participants were initially reluctant to ask questions or make mistakes in front of others for fear of social judgment. "They are afraid to say something or do something wrong," one instructor said. Several other participants focused on computing solutions that were quick to complete, avoiding challenges that could deepen their learning. "I focus on things I can understand and do quickly," one student said.

Early data suggests that the BRIGHT-CS ecosystem has the potential to counteract these messages, through implicit countermessaging from mentors. All of the seven aforementioned mentors demonstrated an approach to mentoring that focused on participants' assets and sent implicit messages to participants about their value to CS. For example, mentors reported inviting participants to demonstrate their CS expertise by asking them to show off their work, share their ideas for problems the mentors were trying to solve in their own work, or teach mentors about something they know; as well as by asking participants about their other interests and highlighting connections to CS. One mentor concluded the first semester by presenting cards that named a different strength that she saw each participant display during the semester. These subtle reversals of stereotypes about deficits did not go unnoticed by participants, several of whom mentioned them as being among their favorite aspects of the BRIGHT-CS program. "[Our mentor] told us about her project to teach kids with games, and I thought maybe I could give her some advice," said one participant. "I would teach her how she can use websites to create a game for kids they'll actually like." At the site where afterschool instruction was led by a mentor, several participants also remarked on the value their mentor placed on each individual's learning potential. "She doesn't leave anyone behind," one participant said. "She makes sure everyone is on track." According to another participant, this is different from the messages she gets in school. "Some people just move on, but she really took the time to understand each of us and make sure we understood the program." Though a few mentors said they had explicit conversations with students about overcoming prejudice, most focused on how to send implicit signals to participants about their value and potential as girls of color in CS. As one instructor put it, "They know they're Black and female, you don't have to tell them the obvious. I believe you need subtle messages to reverse the messages that tell you you're worthless. You have to subtly create an environment where being Black and female [in STEM+CS] becomes cool."

\subsection{Explicit messaging about personal challenges and improvement}

Implicit counter-messages are important but insufficient to support persistence. Oyserman and her colleagues found that to commit effort to a future self, students must believe the self is possible for them to attain, which depends on learning to interpret difficulty encountered as normal to achieving that self [24]. This is relevant to BRIGHT-CS participants. Not only did many participants give indications that they initially believed their encounters with difficulty would draw negative judgment; several also explicitly named experiences of difficulty as a reason they were "not good" at a subject. To meet students' personal experiences of difficulty with explicit messages about the meaning of those experiences (e.g., 'challenges help us grow;' 'growth is as important as success;' 'when facing a challenge, I am resourceful') can help students to develop a growth mindset and persist through difficulty towards the future self $[24,25]$. Oyserman's research suggests that if students are primed by stereotype threat based on membership in a marginalized group (e.g., students of color; girls in STEM), it may also help to have social reinforcement for those messages from same-group members [24].

Again, early data suggest that the BRIGHT-CS ecosystem has potential to deliver both the messages and social reinforcement needed to nurture persistence. By the end of the first semester, 
nearly a dozen participants across all sites reported having had a challenging experience where they persisted by initiating contact with a mentor, instructor or cohort peer to ask for specific knowledge or skills they needed to learn to overcome the challenge [25]. For three of these students, this resourcefulness and help-seeking behavior was especially significant given their initial reluctance to ask questions for fear of social judgment. For a fourth student, it meant she had taken on a challenge in the first place-especially significant because she had avoided doing this at the beginning of the semester. More than half of the students named these experiences when asked to name what they most liked or found helpful about the program, revealing their significance to the participants themselves. Three participants even demonstrated new metacognitive awareness that experiences of difficulty, if followed up with questions, can be a source of new learning. "I learned a lot from that about mistakes we could make and how to fix that," one student said. "[The thing about the program that helped me to learn most was] asking for help and trying it. Even if you messed up, you can go and fix it. Like trial and error," another said. "I don't really ask questions, but I need to start working on that because otherwise I won't be able to understand. I started asking more questions to help with my project; it actually helped," another said.

While there is no way to entirely attribute these interpretations of difficulty to the program, there are promising signs that BRIGHT-CS contributes to these interpretations, by sending participants explicit messages about the meaning of their personal experiences of difficulty. Several participants cited these messages directly, describing how mentors shared personal stories or asked questions that led them to interpret or approach a challenge in a new way. For example, two participants cited mentors' emphasis on the value of questions as a reason they now planned to approach others for help with a challenge. "[Our mentor] constantly asks us if we have questions," said one student. "She makes it kind of comfortable that we can ask any question. So, I feel like if I do, people won't make fun. It feels like a safe environment." During interviews, mentors mentioned messages they had tried to send students that, in many cases, were about experiences of difficulty or the value of incremental growth. "A student was talking about being stressed about taking [the state exam] and how so much is placed on the score you get," said one mentor. In response, she talked about her own experience of overcoming failure in her $\mathrm{PhD}$ program. "I let them know that even in failures, there's something you learn from the failures." Students who told mentors about making progress or overcoming a challenge on a CS project were enthusiastically praised (e.g., "I'd say, 'Wow, you did a lot in a short period!'”).

There are also signs that it mattered for students to receive these messages from same-group members-namely, other girls and women of color who are also interested in STEM+CS. One staff sponsor observed that participants at his site asked samegroup mentors an unusually high number of questions. "I think it's the connection with people who look like them. There is an automatic connection if you have the same experience and they look like you." Though participants themselves very rarely mentioned mentors' race or gender in interviews, their enthusiasm for the same-group mentors-especially those from STEM+CS professional pathways (versus community members from different fields)-was consistent and high, with several students explicitly citing how "comfortable" and natural ("not serious") the interactions with these mentors felt. "They're also sort of a friend, not just a mentor," one student said. "It gives me more trust to tell them stuff that's going on around me. They listen to my problems." By contrast, in sites that also had outgroup mentors, almost no students mentioned these mentors in interviews. Interestingly, in sites where the cohorts included a significant number of Latinx students being mentored by Black women, the mismatch in racial identity did not appear to dampen students' enthusiasm for mentorship. What appeared more important to students was the mentors' approach to mentoring (e.g., "supportive," "encouraging," "helps me"). As previously shown, of course, the mentors' approach to mentoring was highly informed by their experience of stereotype threat as women of color. Because this experience, rather than their specific racial group, seemed most salient, this paper defines 'same-group' to mean girls/women of color in general.

Social reinforcement also came from same-group members in the peer cohort. At two of the four sites, the theme of participants using one another as a resource for overcoming challenges in their CS projects came up more often over time. This suggests that, by the end of the first semester, participants at these sites did not feel they risked judgment for revealing their challenges to one another and provided widespread reinforcement among themselves for the idea that difficulty is a normal part of learning. "We support each other," one student said. Developing positive relationships with one another-a top-reported first-semester outcome among participants in these sites-seemed to be strongly associated with this. "BRIGHT-CS helped me build relationships, so whenever I needed help with anything, I would ask, can you help me with this," one student explained.

Several students mentioned that it was important to them that their cohort peers were also girls, and two others described a feeling of "comfort" among their peers that-though not explicitly tied to gender or race-echoed similar feelings about the samegroup mentors described above. "I feel like I can express myself now [that I'm] closer to the others here," one said. At these sites, it appears that aspects of same-group membership were important to the development of new relationships. These relationships allowed for social reinforcement of the positive aspects of learning from challenges. This is perhaps because participants in these sites were frequently the only girls of color in their classes with an interest in STEM+CS. In the remaining two sites-both all-girls schools serving predominantly students of color-there did not appear to be a strong effect from the cohort, which perhaps felt no different to participants than a regular class.

\subsection{Together, implicit and explicit messaging can move girls of color from naive confidence to authentic self-efficacy}

On the pre-program survey, nearly three-quarters of participants expressed high confidence in their ability to learn CS, suggesting a strong sense of self-efficacy. However, as described above, 
subsequent interviews and observations revealed a more complex situation, with many students initially showing indicators of low efficacy at the first sign of difficulty in the program. Promisingly, there are indications that after six months of programming, more students have moved beyond naive confidence to feelings of authentic self-efficacy in CS. By the end of the first semester, three themes emerged during student reflections on their work in BRIGHT-CS that illustrate a sense of self-efficacy based on real experiences of challenge in CS:

"I figured it out and fixed it." Ten students mentioned with satisfaction an experience of having encountered a problem and "figured it out myself." Participants especially spoke about fixing errors, which several went on to describe as an opportunity for learning rather than a nuisance to avoid. One student explained, "When I got stuck, I just kept trying new things. Even though sometimes I knew it wasn't going to work, I still wanted to try it. Because it's a trial and error process, and it's actually kind of fun." Through statements like these, students implied not only that they now see encountering problems as a normal part of CS, but that they also believe that they have the tools (e.g., "trial and error") they need to be able to "figure out" other problems in the future.

I made something that "works." Six participants expressed pride over having been able to make a working technology product. While their products varied in sophistication, what mattered to participants was only that they were fully self-authored (i.e., I/we made it from top to bottom) and that they successfully performed a computing function (i.e., "it works"). Some participants noted they had been unable to make these things just months or weeks before, and several expressed that they had exceeded their expectations for what they could make. Worth noting is that all of these products involved debugging and other challenging experiences and that students judged themselves not on these experiences, but on the successful product of their persistence. "It takes me a little second to process what's going on," one student reflected. "But it's really cool when it gets all done."

"I'm improving." Seven students described how they improved on past performance or planned to do so in the future, especially by making improvements to their computing products. Not satisfied to have a product that worked, many of these students pursued additional learning in order to add new functionality to make their product more useful for themselves and others. Two participants even expressed awareness that tackling challenges like this was an opportunity to extend their own learning. One student explained, "To add mobile [features to my product] is a lot of complicated stuff, but it's going to help me. Now the challenge is just to learn a new skill to do the next step."

\section{Conclusion and Recommendations}

This paper showcases the interim results of the BRIGHT-CS framework, a CS learning ecosystem designed to promote and support interest in STEM+CS among middle school girls of color, and in particular Black girls of color. The limitations of the study include methodological, conceptual, and implementation issues. Methodologically, the study is an observational design with no comparison group of students. While this research focuses on change over time, without a comparison group of students, it cannot determine impacts of a program. Conceptually, the model pilots a CS learning ecosystem approach with a focus on creating a student program in the first phase. The goal is to continue to build the ecosystem to address outputs as well. The research team also seeks to understand the impact of other student programs that are not part of BRIGHT-CS for middle school girls of color. For implementation, instructors and mentors noted that student attendance was a problem. In fact, only $58 \%$ of girls completed the afterschool program. The interview data reflects data from students who attended the program, not students who attrited.

The results, though interim in nature, highlights potential in a learning ecosystem approach to building and sustaining interest in CS. Within the ecosystem approach, BRIGHT-CS created culturally empowering curriculum that highlights women or girls of color using technology, recruited Black women in computing as mentors and instructors, recruited school staff who were teachers of color, and supported instructors to use culturally responsive practices. Within this ecosystem, the research team found that empowerment demands more than a curriculum featuring other women or girls of color. The value of the ecosystem is in being surrounded by implicit and explicit messaging from instructors, mentors, and positive in-group peers. Student interviews revealed that for many of the girls, they are often the only, or one of a few, girls of color in their advanced (or gifted) STEM classes in their school, and their teachers in their school are predominantly White. It may be difficult for girls of color to experience a learning environment that provides such implicit and explicit messaging of success. More research is needed to understand how schools can provide such a learning environment for girls.

This study found that while mentoring can provide explicit and implicit messaging outside of school settings (such as afterschool or summer experiences), the important factor was not the demographics of the instructors and mentors. Rather, impactful mentors shared their own narratives and story as women of color on the pathway to a STEM+CS profession and in leadership positions. The narratives were not about how "they made it" but on growth, perseverance, and a shared experience. Their approach to building relationships with girls was the assumption that the girls already had aptitude. As one mentor said, "the biggest thing that impacted me as a Black girl growing up and trying to get into STEM was having people understanding where I was coming from. That I already know things, I'm already a critical thinker, creative; that there are these skills I already have that I can apply." In essence, girls of color are already seen as successful with high aptitude. There is no need for stereotype threat [20]. This research found that mentors need not belong to the same racial/ethnic group as mentees, as long as they belong to a group with experiences of racial/ethnic prejudice to inform their approach to mentoring. The success of an ecosystem depends not on finding a "perfect" match for students' demographic identities, but on the participation of instructors and mentors who have these qualities and can share their lived experiences. 


\section{ACKNOWLEDGMENTS}

This research was funded by the National Science Foundation (Award \# 1752436).

\section{REFERENCES}

[1] National Science Board, Science and Engineering Indicators 2016 (NSB-2016-1). 2016, National Science Foundation: Arlington, VA.

[2] Google Inc. and Gallup Inc., Diversity Gaps in Computer Science: Exploring the Underrepresentation of Girls, Blacks, and Hispanics. 2016, Google Inc.: Mountain View, CA.

[3] Eccles, J.S., et al., Development during adolescence: The impact of stage-environment fit on young adolescents' experiences in schools and in families. American Psychologist, 1993. 48(2): p. 90-101.

[4] Google Inc. and Gallup Inc., Searching for Computer Science: Access and Barriers in U.S. K-12 Education. 2015, Google Inc.: Mountain View, CA.

[5] Computer Science Teacher Association, Bugs in the System: Computer Science Teacher Certifications in the U.S. 2013, Computer Science Teacher Association, Association for Computing Machinery: New York, New York.

[6] Battey, D. and L.A. Leyva, A framework for understanding whiteness in mathematics education. Journal of Urban Mathematics Education, 2016. 9(2): p. 49-80.

[7] Le, P.T. and C.E. Matias, Towards a truer multicultural science education: How whiteness impacts science education. Cultural Studies of Science Education, 2018. 14(1): p. 15-31.

[8] McFarland, J., et al., The Condition of Education 2018 (NCES 2018-144). 2018, US Department of Education National Center for Education Statistics: Washington DC.

[9] United States Government Accountability Office, K-12 Education Discipline Disparities for Black Students, Boys, and Students with Disabilities (GAO-18-258). 2018, US Government Accountability Office: Washington DC.

[10] Blanchett, W.J., Disproportionate representation of African American students in special education: Acknowledging the role of white privilege and racism. Educational Researcher, 2006. 35(6): p. 24-28.

[11] Grissom, J.A. and C. Redding, Discretion and disproportionality: Explaining the underrepresentation of high-achieving students of color in gifted programs. AERA Open, 2016. 2(1): p. 1-25.

[12] Zhang, D., et al., Minority representation in special education: 5-year trends. Journal of Child and Family Studies, 2014. 23: p. 118-127.

[13] Bailey, D., et al., Persistence and fadeout in the impacts of child and adolescent interventions. Journal of Research on Educational Effectiveness, 2017. 10(1): p. 7-39.

[14] Morris, P.A. and S.F. Reardon, Moving education science forward by leaps and bounds: The need for interdisciplinary approaches to improving children's educational trajectories. Journal of Research on Educational Effectiveness, 2017. 10(1): p. 1-6.

[15] National Research Council, Identifying and Supportive Productive STEM Programs in Out-of-School Settings. 2015, The National Academies Press: Washington DC.

[16] Traphagen, K. and S. Traill, How Cross Sector Collaborations are Advancing STEM Learning. 2014, Noyce Foundation: Los Altos, CA.

[17] Nakkula, M.J. and E. Toshalis, Understanding Youth: Adolescent Development for Educators. 2006, Cambridge, MA: Harvard Education Press.

[18] Durlak, J.A. and R.P. Weissberg, The impact of after-school programs that promote personal and social skills. 2007, Collaborative for Academic, Social, and Emotional Learning: Chicago, IL.
[19] Brummelman, E. and S. Thomaes, How children construct views of themselves: A social-development perspective. Child Development, 2017. 88(6): p. 1736-1773.

[20] Steele, C.M. and J. Aronson, Sterotype threat and the intellectual test performance of African Americans. Journal of Personality and Social Psychology, 1995. 69: p. 797-811.

[21] Clance, P.R., The Imposter Phenomenon: Overcoming the Fear that Haunts Your Success. 1985, Atlanta, GA: Peachtree Publishers.

[22] Young, J.L., J.R. Young, and D.Y. Ford, Standing in the gaps: Examining the effects of early gifted education on black girl achievement in STEM. Journal for Multicultural Education, 2017. 28(4): p. 290-312.

[23] Epstein, R., J. Blake, and T. Gonzalez, Girlhood Interrupted: The Erasure of Black Girls' Childhood. 2017, Georgetown University, Georgetown Law Center on Poverty and Inequality: Washington DC.

[24] Oyserman, D., L. Gant, and J. Ager, A socially contextualized model of African American identity: Possible selves and school persistence. Journal of Personality and Social Psychology, 1995. 69(6): p. 12161232.

[25] Dweck, C.S., Mindset: The New Psychology of Success. 2006, New York: Random House.

[26] Scott, K.A. and M. White, COMPUGIRLSs standpoint: Culturally responsive computing and its effect on girls of color. Urban Education, 2013. 48(5): p. 657-681.

[27] Ladson-Billings, G., Toward a theory of culturally relevant pedagogy. American Educational Research Journal, 1995. 32(3): p. 465-491.

[28] Ryoo, J., J. Goode, and J. Margolis, It takes a village: Supporting inquiry- and equity-oriented computer science pedagogy through a professional learning community. Computer Science Education, 2015. 25(4): p. 351-370.

[29] Steele, C.M., S.J. Spencer, and M. Lynch, Self-image resilience and dissonance: The role of affirmational resources. Journal of Personality \& Social Psychology, 1993. 64(6): p. 885-896.

[30] Hattie, J. and H. Timperley, The power of feedback. Review of Educational Research, 2007. 77(1): p. 81-112.

[31] Bransford, J., et al., Learning theories and education: Toward a decade of synergy, in Handbook of Educational Psychology P.A. Alexander and P.H. Winne, Editors. 2006, Lawrence Erlbaum Associates: Mahwah, NJ. p. 209-244.

[32] Ong, M., et al., Inside the double bind: A synthesis of empirical research on undergraduate women of color in science, technology, engineering, and mathematics. Harvard Educational Review, 2011. 81(2): p. 172390.

[33] US Department of Education Office of Planning Evaluation and Policy Development Policy and Program Studies Service, The State of Racial Diversity in the Educator Workforce. 2016, US Deparmtent of Education: Washington DC.

[34] Google Inc. and Gallup Inc., Images of Computer Science: Perceptions among Students, Parents, and Educators in the U.S. 2015, Google Inc.: Mountain View, CA.

[35] Hill, C.E., et al., Consensual qualitative research: An update. Journal of Counseling Psychology, 2005. 52(2): p. 196-205.

[36] Saldana, J., The Coding Manual for Qualitative Researchers. 2009, Thousand Oaks, CA: Sage Publications.

[37] Huberman, A.M. and M.B. Miles, Data Management and Analysis Methods, in Handbook of Qualitative Research, N.K. Denzin and Y.S. Lincoln, Editors. 1994, Sage: Thousand Oaks, CA. p. 428-443.

[38] Morrow, S., Quality and trustworthiness in qualitative resaerch in counseling psychology. Journal of Counseling Psychology, 2005. 52(2): p. 250-260. 